\title{
HEALTH EDUCATION AND DISEASE PREVENTION PROGRAMME IN AN UNDERDEVELOPED AREA CUSICHACA PROJECT PERU, 1979
}

\author{
MAJ P R T HEWETSON, MB, BCh, BAO, DRCOG, RAMC \\ Group Practice, Tidworth
}

SUMMARY: A description is given of the setting up of a health education and disease prevention programme in an underdeveloped area of the Andean highlands of Peru, by an Army doctor who accompanied a 10-man Army team in support of an Archaeological expedition in its second year of a major 5-year programme of archaeological research.

\section{Introduction}

The Cusichaca Project is a five-year Archaeological Project, 1979 being its second year, which, under the Directorship of Dr Ann Kendall, goes out to an area in the Andean highlands in Peru $90 \mathrm{~km}$ north-west of Cusco, for four months every summer. The project team consists of 35 civilians, mostly archaeologists and archaeological volunteers, two thirds British and one third Peruvian, together with a botanist and anthropologist. This was supported by a 10-man British Army team in 1979 consisting of a Camp administrator, second in command, chef, two Royal Engineers surveyors, two medical orderlies, photographer, general handyman and a doctor. This was the first time a doctor had accompanied the project.

The aims of the project were twofold: (i) Archaeological and botanical research; (ii) Rehabilitation.

\section{Archaeological and botanical research}

Archaeological digging and research were carried out at the nearby Incan and Pre-Incan ruined fort, Hallacaynathay and Incan ruined town of Patallacta. Botanical research included analysis of soil phosphates and pollen.

\section{Rehabilitation}

Rehabilitation involved the repair and operation of two disused Incan canals, with the help of members of the local community whom the reconstruction would benefit, to produce irrigation, fertility and eventually, it is hoped, prosperity to the adjoining valleys, which had once been enjoyed in the Incan era.

It was to this general aim of rehabilitation of the local communities that much time was devoted, and thus the establishment of a Medical project in health education was embarked on.

\section{Medical project}

Lengthy research was carried out with the anthropologist, a fluent Spanish speaker, who was an invaluable help in setting up the programme. It was found that the average mother in the adjoining valleys bore, on average, eight children and retained four. The staple diet was potatoes, with, as was too often the case, one meat meal a month. Water collected from streams was infested, infected. and never boiled. 


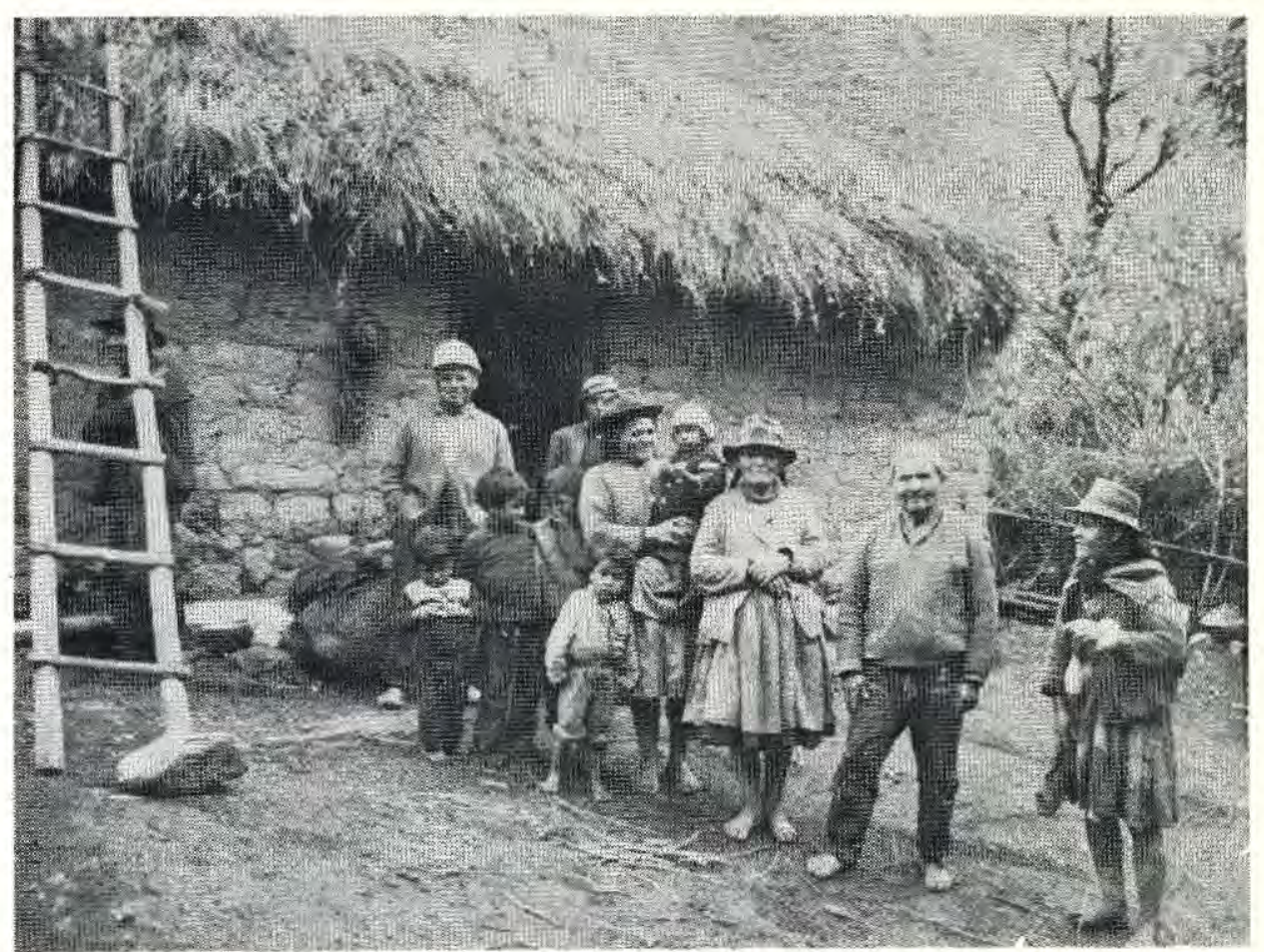

Typical Peruvian Indian family and their home

The statistics, given below, demonstrates how bad the situation was in comparison with the Western World, and also how it became obvious why children became the main target of endeavours.

\section{Statistics}

The infant mortality rate was 30 per cent. Death rate by the age of five years was 50 per cent. The main causes were - malnutrition, diarrhoea, respiratory diseases (including TB) and communicable diseases such as measles. The average life expectancy was 50 years. Sixty per cent of all children throughout Peru are malnourished and this figure is rising.

\section{Aims of project}

The aims of the medical project were to improve nutrition, to educate and improve hygiene, to instruct on the need for clean drinking water and its treatment, and to reduce communicable diseases.

\section{Implementation}

This was the main problem, and one which luckily, a great deal of research was gone into, and a lot of advice received on, before anything was initiated.

Many other groups or individuals had come into the country, and with the best will in the world had attempted to introduce Western ideas in, what appeared to the Peruvian Indian, an arrogant way. They failed to understand the deeply 


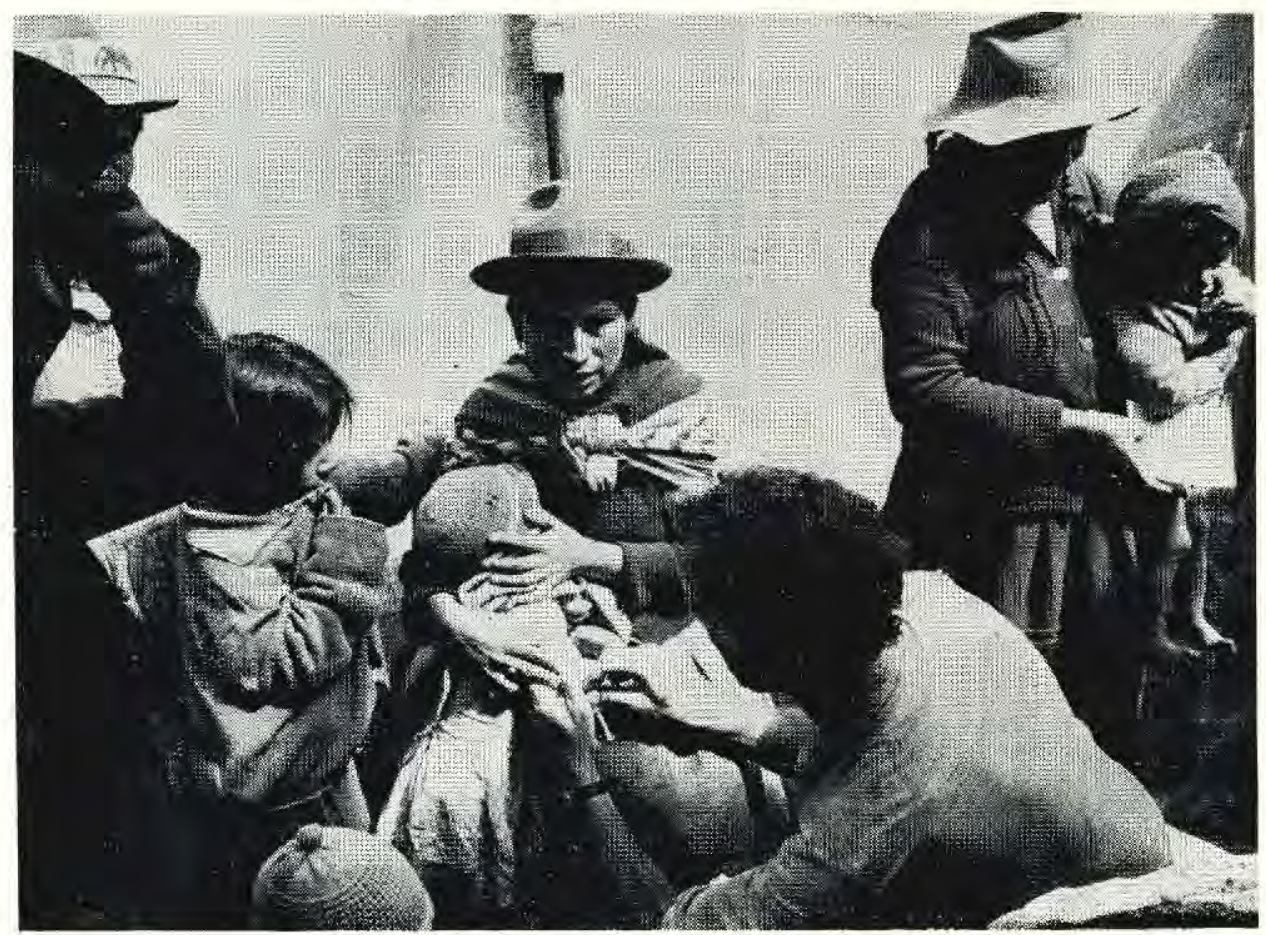

Part of the daily routine

entrenched religious and superstitious beliefs, and lacked a compromising attitude to their inherent traditional following of herbal medicines and 'witch doctors'.

Their approaches were met with suspicion and resistance from the local people and, in particular, the left-wing political factions in the city, who resented outsiders winning the confidence of "their people". It was this latter group that the instigators knew they would have to satisfy if any implemented plan was to succeed at all. This problem had to be gone about, therefore, in a slow, round-about and diplomatic fashion.

After a long meeting with a Peruvian doctor, who was carrying out rehabilitation work in another part of the Cusco region, the practical method of approach was formulated. It is largely due to his advice and help that the programme at Cusichaca had such a degree of success, and due to his guidance, the initial approaches were done in the right way. This involved meeting the Director of the Regional Health Authority, who was enthusiastic and instructed the local health representative to give his backing and assistance in setting up this health education and disease prevention programme, where previously a doctor had never visited. Incidentally, that doctor was later given an office-job in the Ministry of Health in Cusco, to oversee and direct all health programmes in the underdeveloped areas of the Province, which ensured the continuity of the programme after the departure of the British team.

As a result, the representative of the local area Health Authority was met and he and his chief nursing officer met the local Indian community leader who was 
an important link in the chain, and they were shown the local conditions. It was then discussed between them as to what to say to the local population of the valleys, when a meeting could be arranged. Again, the anthropologist was invaluable with his fluent Spanish and insight into the local problems and culture, in deciding what was to be said. During the medical work which was carried out, those inherent superstitions, religious beliefs and herbal medicines were always taken into account and respected. It was realised that any new medicines or ideas would not necessarily be accepted, if at all. The accent was, therefore, on prevention of disease and health education more than cure of disease already contracted, though this was dealt with too. Thus, a stage had been reached of confronting the indigenous community with these plans and ideas, and with this approach it appeared to come from the Ministry of Health and local leaders who supported the ideas. In addition, it placed the responsibility of the continuity and follow-up on the shoulders of those people after our departure.

\section{Subjects tackled}

The subjects tackled were divided into four categories - (i) Malnutrition. (ii) Water supply, collection and purification. (iii) Latrine building. (iv) Vaccination.

Malnutrition. This was a major problem which will take a long time to overcome, mainly due to the necessity to have a constant co-operation by the people, in the need to change the emphasis in their diets. The aim was to include protein, which as mentioned before was primarily potato and also maize. Potato contains 0.8-2.0 per cent protein, and the crops to be introduced were: Tarwi (a legume) -24 per cent, and Quinua (a sort of lentil) -18 per cent, protein.

An agronomist from Cusco was brought in, with free and improved Tarwi and Quinua seeds, as part of a research programme to improve production and nutrition. He taught the men of the community how and when to sow the crop, and reiterated previously repeated emphasis on the need for protein in the diet, be it in a child or breast-feeding mother. This was talked of many times, showing how they could actively reduce their own morbidity and mortality figures.

Interestingly enough, Tarwi was a crop grown by the Incas who, it appears enjoyed a better standard of health as well as prosperity.

Water supply and collection. Straightforwand demonstrations were given in the way which clean water could be obtained from streams. Firstly it was shown how it was necessary to have a 'drop' in water level at the collecting point by means of a shute. This reduced the amount of visible and invisible parasites collected which rested on the stream bed. They were collected in abundance when the women customarily scooped water from the stream bed with a bowl. A jam-jar full of water was shown, which contained visible parasites. A flour bag was then sewn up and the water filtered through it, demonstrating how the bag retained the parasites and emphasizing how it was these 'bugs' which often gave rise to the babies' and childrens' diarrhoea, which, if untreated after three days in the babies was a killer. Boiling this water to kill remaining parasites was then discussed and its importance emphasized.

Latrine building. Excrement was never centralized, therefore the community leader was shown how to build a deep trench latrine using available local materials. He then built one himself, with assistance, and was able to show it proudly to the whole community at the meeting, and told them of the importance of centralization. 
Vaccination. Finally, all the children in the area were vaccinated with BCG and the measles vaccine. There had been a massive measles epidemic in other areas recently, killing a large number of small children. This was done by joint effort of the British and Peruvian medical teams.

\section{Discussion}

It can be seen that the measures proposed were fairly ambitious, in that they involved quite major changes in the life style and daily habits which had been practised for generations. One was always very aware of this, and that is why the enthusiasm of those people who had influence locally was ensured, before they spoke to the community.

The main worry, as is always the problem in a situation like this, is continuity after the departure of outside help. The local Health Authority representatives planned monthly visits, and the Peruvian doctor first approached, now in the Ministry offices in Cusco, will oversee them and try to maintain continuity.

If the rehabilitation programme does get off the ground, both from the agricultural point of view and the health programme, then it is hoped that Cusichaca will be used as a test-ground or show piece, examples of which can be taken by the Government to give similar aid to other undeveloped areas in the future.

A BBC team came out and stayed a week, making a film on the Incan Archaeology to be shown in Great Britain and America at a later date. They showed a lot of interest in the Rehabilitation programme both in the canal building and the medical project. It is hoped that this may spark off support to help these people. This is the main concern of Dr Ann Kendall, for without it the Cusichaca Project may not be able to carry right through.

Co-operation is needed on the one hand from the outsider for technical and financial aid, and on the other hand from the people themselves to change their dietary habits and standards of hygiene, for this work to have been fruitful. It is of great importance that a doctor and an anthropologist accompany the 1980 project to assess the progress made in the first year, and to add momentum to further continuity.

Seeds have at least been sown, but a persistence from all quarters for a long period is the only guarantee that the seeds will bear fruit, and show an appreciable improvement in the morbidity and mortality figures and quality of life, which is the aim.

\section{Acknowledgements}

I would like to thank Dr Oscar Liendo of the Ministerio de Salud at Cusco, who gave so much helpful advice and support in launching this programme, and upon whom we rely a great deal to oversee and ensure continuation of it, and also Luke Holland the Anthropologist, without whose constant help in interpreting and understanding of the Peruvian Indian, this programme would have achieved little. 